\title{
Effect of dithiocyano-methane on hexose monophosphate pathway in the respiratory metabolism of Escherichia coli
}

\author{
Yanfeng Chen, Wenjie Ke, Huabin Qin, Siwei Chen, Limei Qin, Ying Yang, Hui Yu and Yuansheng Tan*
}

\begin{abstract}
This paper studied the inhibitory effects of dithiocyano-methane (DM) on the glucose decomposition pathway in the respiratory metabolism of Escherichia coli. We investigated the effects of DM on the activities of key enzymes (ATPase and glucose-6-phosphate dehydrogenase, G6PDH), the levels of key product (nicotinamide adenosine denucleotide hydro-phosphoric acid, NADPH), and gene expression in the hexose monophosphate pathway (HMP). The results showed that the minimum inhibitory concentration (MIC) and the minimum bactericide concentration (MBC) of DM against the tested strains were $5.86 \mathrm{mg} / \mathrm{L}$ and $11.72 \mathrm{mg} / \mathrm{L}$, respectively. Bacteria exposed to DM at MIC demonstrated an increase in bacterial ATPase and G6PDH activities, NADPH levels, and gene expression in the HMP pathway compared to bacteria in the control group, which could be interpreted as a behavioral response to stress introduced by DM. However, DM at a lethal concentration of $10 \times$ MIC affected glucose decomposition by inhibiting mainly the HMP pathway in E. coli.
\end{abstract}

Keywords: Dithiocyano-methane, Hexose monophosphate pathway, Respiratory metabolism, Escherichia coli

\section{Introduction}

Respiratory metabolism of bacteria is an important manifestation of life activities, and its essence is the oxidation and degradation process of intracellular saccharides. The oxidative metabolism of saccharides is vital to provide the energy needed for cellular activities, the carbon scaffolds for anabolism and the metabolism of bacteria. There are three main pathways of glucose decomposition in bacteria: (1) the glycolysis pathway (EMP) under anaerobic conditions in which lactic acid or ethanol are generated from glucose; (2) the tricarboxylic acid cycle pathway (TCA) under aerobic conditions in which the glucose is completely oxidized to water and carbon dioxide; and (3) the hexose monophosphate pathway (HMP)

\footnotetext{
*Correspondence: ys.fsu.tan@gmail.com

Guangdong Provincial Key Laboratory of Animal Molecular Design and Precise Breeding, Key Laboratory of Animal Molecular Design and Precise Breeding of Guangdong Higher Education Institutes, School of Life Science and Engineering, Foshan University, Foshan 528231, China
}

in which glucose is oxidized to supply cell body with $\mathrm{NADPH}$, ribose and its derivatives (e.g. coenzyme).

Pathogenic Escherichia coli, a zoonotic pathogen of humans and animals, leads to many diseases in humans, poultry and livestock (Woodward et al. 1990; Boudeau et al. 1999; Frydendahl 2002; Mellata et al. 2003; Kwak et al. 2016), posing a great threat to human health and the development of animal husbandry. Disinfectant is currently the primary method to kill pathogenic E. coli in the living environment of humans, poultry and livestock. However, the application of disinfectant to eliminate pathogenic E. coli strains isolated from hospitals, communities, livestock and poultry farms has been limited by the growing problem of drug resistance (Li et al. 2012; Chen and Xia 2013; Yang et al. 2015; Ibrahim et al. 2019). Therefore, it is necessary to search for new solutions to prevent $E$. coli infections.

Dithiocyano-methane (DM, Structural formula: $\left.\mathrm{SCN}-\mathrm{CH}_{2}-\mathrm{SCN}\right)$, also known as methylene bisthiocyanate (Singh et al. 2006; Qi et al. 2008) or methylene dithiocyanate (Chen et al. 2003, 2004), has been used 
as an antifungal agent in plant protection and the aquaculture industry (Chen et al. 2003; Qi et al. 2008; Cao et al. 2012). However, the antibacterial properties of DM against bacteria have been neglected and therefore it has not been widely used in many industries.

The antimicrobial action mechanism of DM has not been fully elucidated. Some studies indicated that DM inhibited the respiration of Fusarium moniliforme and Saccharomyces cerevisiae by affecting the mitochondrial respiration rate and cytochrome oxidase in the electron transport chain (Chen et al. 2003, 2004). Similar results also suggested the effect of DM on Ophiostoma floccosum, which indicated this agent not only inhibited fungal respiratory activity but also reduced ATP level and glucose consumption (Singh et al. 2006). However, no further studies have been carried out on the mechanism of the decrease in microbial glucose consumption in response to DM. This study investigated which glucose decomposition pathway is inhibited and how this pathway is affected in $E$. coli when exposed to DM. The goal of current study is to elucidate the antimicrobial mechanism of DM, investigate the antibacterial effectiveness of DM against $E$. coli, and provide a reference for its application as an antibacterial agent.

\section{Materials and methods Materials}

Dithiocyano-methane (DM) was purchased from Guangzhou Kafen Biotechnology Co., Ltd. Escherichia coli standard strain CFT073, deposited in the American Type Culture Collection (ATCC 700928), and E. coli strain O157, isolated from diseased pigs, were kindly donated by Dr. Liu Canying from Foshan University. Two different strains were used to determine the minimum inhibitory concentration (MIC) and minimum bactericide concentration $(\mathrm{MBC})$, while only strain CFT073 was used to carry out the rest experiments.

The purified strain was maintained at $-80{ }^{\circ} \mathrm{C}$ in sterile nutrient broth containing $30 \%$ glycerol. The bacteria were streaked on nutrient agar plates and incubated at $37^{\circ} \mathrm{C}$ for $24 \mathrm{~h}$. A sterilized loop was used to transfer the colonies to sterile nutrient broth in a test tube one day before the experiment. The culture was incubated on a shaker $(100 \mathrm{rpm})$ at $37^{\circ} \mathrm{C}$ overnight. Bacteria in the logarithmic growth phase were used in the experiments.

DM of $0.3 \mathrm{~g}$ was dissolved in sterile distilled water $(100 \mathrm{~mL})$ by slow heating below $70{ }^{\circ} \mathrm{C}$ with stirring. After cooling to room temperature, the solution was sterilized by filtration through $0.22 \mu \mathrm{m}$ filter membranes. The stock solution was stored at $4{ }^{\circ} \mathrm{C}$.

\section{Determinations of MIC and MBC}

The MIC was determined using a two-fold-brothdilution method by following the National Committee for Clinical Laboratory Standards reference method (NCCLS 2000). Stock solution of DM was added to nutrient broth to obtain final concentrations of 187.5, $93.75,46.88,23.44,11.72,5.86,2.93,1.46,0.73$ and $0.37 \mathrm{mg} / \mathrm{L}$, respectively. E. coli CFT073 was incubated and adjusted to $2.95 \times 10^{8} \mathrm{CFU} / \mathrm{mL}$. Then $100 \mu \mathrm{L}$ of bacterial suspension was added to the above-mentioned mixtures with different concentrations in proper order followed by incubation at $37^{\circ} \mathrm{C}$ for $24 \mathrm{~h}$. The mixture containing nutrient broth and bacteria without DM was used as the control group. Aliquots of $100 \mu \mathrm{L}$ of cultures were removed from the nonvisible bacterial growth tubes and then spread on the surface of nutrient agar. The MBC was defined as the lowest concentration of DM, where no growth was observed after the cells were incubated on nutrient agar plates at $37{ }^{\circ} \mathrm{C}$ for $48 \mathrm{~h}$ (Ma et al. 2010). The same method was used to determine the MIC and MBC of DM against E. coli strain O157.

\section{Respiration inhibition of DM at a lethal concentration of $10 \times$ MIC against E. coli CFT073}

The respiration inhibition test was carried out according to previous studies with modifications (Guo et al. 2005; Ma et al. 2010; Qu et al. 2015). A mixture containing $1.6 \mathrm{~mL}$ of $1 \%$ glucose, $14.4 \mathrm{~mL}$ of PBS and $4 \mathrm{~mL}$ of E. coli CFT073 bacterial suspension in the logarithmic growth phase was stirred lightly for $5 \mathrm{~min}$ in a reagent bottle sealed with a preservative film. During the experiment, each reagent bottle was continuously stirred. Oxygen consumption was gauged by a JPB-607A dissolved oxygen analyzer (Leici, INESA Scientific Instrument Co., Ltd, Shanghai, China) at $2.5 \mathrm{~min}$ intervals for $5 \mathrm{~min}$, obtaining the initial respiratory rate $\left(\mu \mathrm{mol} \mathrm{O}_{2} \mathrm{~g}^{-1} \mathrm{~min}^{-1}\right)$. Then, the stock solution of DM was added to the abovementioned mixture, in which the final concentration of $\mathrm{DM}$ was $58.6 \mathrm{mg} / \mathrm{L}(10 \times \mathrm{MIC})$. According to the respiratory rate of $E$. coli CFT073 before and after DM addition, the respiratory inhibition rate of E. coli CFT073 was calculated using the following equation:

$$
I_{R}=\frac{R_{0}-R_{1}}{R_{0}} \times 100 \%
$$

where, $I_{R}$ is the respiratory inhibition rate of $E$. coli CFT073 after DM addition, and $R_{0}$ and $R_{1}$ is the respiratory rate of E. coli CFT073 before and after DM addition, respectively.

Three typical inhibitors, iodine acetic acid, malonic acid, and sodium phosphate, were used in the 
experiment. The inhibitory superposition rate of $E$. coli CFT073 was calculated using the following equation:

$$
D_{R}=\frac{R_{1}-R_{2}}{R_{1}} \times 100 \%
$$

where, $D_{R}$ is the inhibitory superposition rate of $E$. coli CFT073; $R_{1}$ is the respiratory rate of E. coli CFT073 after DM addition; $R_{2}$ is the respiratory rate of E. coli CFT073 after the addition of inhibitor and DM.

\section{Activities of ATPase and glucose-6-phosphate dehydrogenase (G6PDH) in E. coli CFT073 exposed to DM at a concentration of MIC}

DM was added to the bacterial suspension of $E$. coli CFT073 in the logarithmic growth phase with the final concentration of MIC. After exposure for 0, 1, 4, $24 \mathrm{~h}$, the activities of ATPase and G6PDH were determined according to the instruction of the test kits (Jiancheng, Nanjing Jiancheng Bioengineering Institute, Nanjing, China \& Keming, Suzhou Comin Biotechnology Co., Ltd, Suzhou, China) by ultraviolet spectrophotometer.

\section{Levels of nicotinamide adenosine denucleotide} hydro-phosphoric acid (NADPH) in E. coli CFT073 exposed to DM at a concentration of MIC

DM was added to the bacterial suspension of E. coli CFT073 in the logarithmic growth phase with the final concentration of MIC. After exposure for 0, 1, 4, 24 h, the levels of NADPH were determined according to the instruction of the test kit (Keming, Suzhou Comin Biotechnology Co., Ltd, Suzhou, China) by ultraviolet spectrophotometer.

\section{Real-time quantitative PCR (RT-qPCR) analysis} of the expression of genes in the HMP pathway and genes related to the stress response

DM was added to the bacterial suspension of $E$. coli CFT073 in the logarithmic growth phase with the final concentration of MIC. After exposure for 0, 1, 4, $24 \mathrm{~h}$, bacterial suspensions were sampled. Total RNA was extracted from the bacterial cells using the EasyPure RNA Kit (TransGen Biotech, Transgen Biotechnology Co., LTD, Beijing, China). Total RNA of $1 \mu \mathrm{g}$ was used for cDNA synthesis with the PrimeScript ${ }^{\mathrm{TM}}$ II 1st Strand cDNA Synthesis Kit (Takara, Takara Biotechnology (Dalian) Co., Ltd, Dalian, China). RT-qPCR was carried out in a 96-well plate using the SYBR ExScript RT-qPCR Kit (Takara, Takara Biotechnology (Dalian) Co., Ltd, Dalian, China) as described previously (Hu et al. 2010). The expression level of genes in Table 1 was analyzed using the comparative threshold cycle method $\left(2^{-\triangle \triangle \mathrm{CT}}\right)$ with $16 \mathrm{~S}$ rDNA as control. All data are relative mRNA expressed as means \pm standard deviations.

\section{Statistical analysis}

All experiments were performed in triplicate or more. Values were expressed as means and standard deviations. Statistical analysis was performed on SPSS 19.0 software, and probability levels of less than 0.05 were considered statistically significant $(P<0.05)$.

\section{Results}

MIC and MBC of DM against the tested $E$. coli strains

In the present study, the MIC and MBC value of DM against two E. coli strains were $5.86 \mathrm{mg} / \mathrm{L}$ and $11.72 \mathrm{mg} / \mathrm{L}$, respectively.

\section{Respiration inhibition of DM at a lethal concentration of $10 \times$ MIC against E. coli CFT073}

As shown in Table 2, the inhibitory superposition rate of malonic acid, sodium phosphate, iodine acetic acid and DM was $(74.82 \pm 7.14) \%,(30 \pm 12.02) \%$ and $(60.74 \pm 5.59) \%$, respectively.

\section{Activities of ATPase and G6PDH in E. coli CFT073 exposed to DM at a concentration of MIC}

The effects of DM on the ATPase activities of E. coli CFT073 are presented in Fig. 1. The ATPase activities in exposed group increased significantly at $1 \mathrm{~h}$ and $4 \mathrm{~h}$ compared to $0 \mathrm{~h}(P<0.05)$. The ATPase activities of $E$. coli CFT073 in exposed group were significantly higher than those in control group at $1 \mathrm{~h}, 4 \mathrm{~h}$ and $24 \mathrm{~h}(P<$ 0.05).

As shown in Fig. 2, there were no significant differences in G6PDH activities of E. coli CFT073 in exposed group at different times $(P>0.05)$. However, the G6PDH activities in exposed group were significantly higher than those in control group at $4 \mathrm{~h}$ and $24 \mathrm{~h}(P<$ 0.05).

\section{NADPH levels in E. coli CFT073 exposed to DM at a concentration of MIC}

As shown in Fig. 3, the NADPH levels of E. coli CFT073 in exposed group at $4 \mathrm{~h}$ and $24 \mathrm{~h}$ were significantly lower than those at $0 \mathrm{~h}$ and $1 \mathrm{~h}(P<0.05)$. The NADPH levels in exposed group were significantly higher than those in control group at $4 \mathrm{~h}(P<0.05)$. The NADPH levels were very low in both control and exposed groups at $24 \mathrm{~h}$.

\section{RT-qPCR analysis of the expression of genes in the HMP pathway}

The effects of DM on the expression of genes in the HMP pathway of E. coli CFT073 are presented in Fig. 4. It showed that DM led to a significant up-regulation of the expression of all genes for $1 \mathrm{~h}, 4 \mathrm{~h}$ and 
Table 1 Primers used in this study

\begin{tabular}{|c|c|c|}
\hline Gene & Primer sequences $\left(5^{\prime} \rightarrow 3^{\prime}\right)$ & $\begin{array}{l}\text { Accession } \\
\text { number } \\
\text { in NCBI }\end{array}$ \\
\hline Fructose-bisphosphate aldolase (fbaA) & $\begin{array}{l}\text { (F) AACGTGGTTCTGACTCCGAC } \\
\text { (R) GAAGTTCAGGCTGTTGTGCG }\end{array}$ & NC_000913 \\
\hline Fructose-1,6-bisphosphatase (fbp) & $\begin{array}{l}\text { (F) TGGATGGCTCGTCCAACATC } \\
\text { (R) TATACCACGTAACCTGCCGC }\end{array}$ & EU890589 \\
\hline Ribose-5-phosphate isomerase (rpiA) & $\begin{array}{l}\text { (F) GCACACTTTATTGACGCGCT } \\
\text { (R) GGCTGTCGACTTCGTTGAGA }\end{array}$ & NC_011751 \\
\hline 6-phosphogluconolactonase (pgl) & $\begin{array}{l}\text { (F) GATGGTCATCTGGTGGCACA } \\
\text { (R) CCCAGACATCCACTGAGCTG }\end{array}$ & NC_011751 \\
\hline Transketolase A ( $t k t A)$ & $\begin{array}{l}\text { (F) TCGACTGAACATAGCGGTCG } \\
\text { (R) GACAGTGGCCTGTGCTAACT }\end{array}$ & JQ582675 \\
\hline Transaldolase A (talA) & $\begin{array}{l}\text { (F) ACAGCGGCGATATTGAGTCCATTC } \\
\text { (R) CTGCGACCACCTGTTGTTCCTG }\end{array}$ & NC_011750 \\
\hline Triosephosphate isomerase (tpiA) & $\begin{array}{l}\text { (F) TGGCTGCCGGTATTGGTTAC } \\
\text { (R) ATCCGGCATTGGGTTTGACT }\end{array}$ & EU891919 \\
\hline 6-phosphogluconate dehydrogenase (gnd) & $\begin{array}{l}\text { (F) AGCAACAGATCGGCGTAGTC } \\
\text { (R) TCTTCTCACGGGAACGGTTG }\end{array}$ & M23181 \\
\hline Glucose-6-phosphate dehydrogenase (zwf) & $\begin{array}{l}\text { (F) TACTTCGAGGAGTGCCAGGT } \\
\text { (R) CAGCAGGTGGTTCTGGATCA }\end{array}$ & EU899540 \\
\hline 165 rDNA & $\begin{array}{l}\text { (F) CGTCGTAGTCCGGATTGGAG } \\
\text { (R) TCACCGTGGCATTCTGATCC }\end{array}$ & \\
\hline rpos & $\begin{array}{l}\text { (F) GGTCTGGCGTTGCTGGATCTTATC } \\
\text { (R) ACCAGGTTGCGTATGTTGAGAAGC }\end{array}$ & NC_011750 \\
\hline marA & $\begin{array}{l}\text { (F) CCTGGAATCGCCACTGTCACTG } \\
\text { (R) ATCTTACGGCTGCGGATGTATTGG }\end{array}$ & NC_011750 \\
\hline soxs & $\begin{array}{l}\text { (F) GCCAACGCCGCCTGTTACTG } \\
\text { (R)GAAGGTCTGCTGCGAGACATAACC }\end{array}$ & NC_011750 \\
\hline
\end{tabular}

Table 2 Effect of dithiocyano-methane on the respiration inhibition of $E$. coli CFT073

\begin{tabular}{|c|c|c|}
\hline \multirow[t]{2}{*}{ Inhibitor } & \multicolumn{2}{|l|}{ E. coli CFT073 } \\
\hline & $\begin{array}{l}\text { Respiratory } \\
\text { inhibition rate }\left(I_{R}\right)\end{array}$ & $\begin{array}{l}\text { Inhibitory } \\
\text { superposition } \\
\text { rate }\left(D_{R}\right)\end{array}$ \\
\hline Dithiocyano-methane & $42.73 \pm 2.39$ & - \\
\hline Sodium phosphate & $26.11 \pm 6.73$ & $30 \pm 12.02^{a}$ \\
\hline lodine acetic acid & $44.81 \pm 5.01$ & $60.74 \pm 5.59^{b}$ \\
\hline Malonic acid & $55.19 \pm 5.01$ & $74.82 \pm 7.14^{b}$ \\
\hline
\end{tabular}

Different letters indicate significant differences among different superpositions $(P<0.05)$

$24 \mathrm{~h}$ compared to $0 \mathrm{~h}$. The expression levels of $f b a A$, $t k t A$ and gnd gene were up-regulated gradually after exposure to DM (Fig. 4a, e, h). The expression levels of $p g l$, talA and tpiA gene were first up-regulated and then down-regulated (Fig. $4 \mathrm{~d}, \mathrm{f}, \mathrm{g}$ ). In addition, the expression levels of $f b p$ and $z w f$ gene were up-regulated significantly at $1 \mathrm{~h}(P<0.05)$, whereas there were no significant changes in their expression levels after $4 \mathrm{~h}(P$ $>0.05$ ) (Fig. 4b, i). There was no significant difference in the expression levels of rpiA among $1 \mathrm{~h}, 4 \mathrm{~h}$ and $24 \mathrm{~h}(P$ $>0.05)$ (Fig. 4c).

\section{RT-qPCR analysis of the expression of genes related to the stress response}

The results in Fig. 5 show the effects of DM on the expression of genes related to the stress response of $E$. coli CFT073. The expression levels of marA and rpoS genes were up-regulated significantly at $1 \mathrm{~h}$ and $4 \mathrm{~h}$ while down-regulated significantly at $24 \mathrm{~h}$ compared to $0 \mathrm{~h}(P$ $<0.05$ ) (Fig. $5 \mathrm{k}, \mathrm{j}$ ). Furthermore, the expression levels of the soxS gene were up-regulated significantly at the $1 \mathrm{~h}$ and $4 \mathrm{~h}(P<0.05)$, whereas there was no significant difference in the expression levels between 0 and $24 \mathrm{~h}(P>$ 0.05) (Fig. 5 l).

\section{Discussion}

Toxicity and stability of DM

Although DM in powder form is harmful to the human body (Braun et al. 2006), the products formed after degrading DM in aqueous solution are non-toxic thiocyanate ions and formaldehyde, and the latter can be further oxidized to carbon dioxide under aerobic conditions (Qi et al. 2006), resulting in low environmental residue 


\section{$\square$ Control group $\square$ Exposed group}

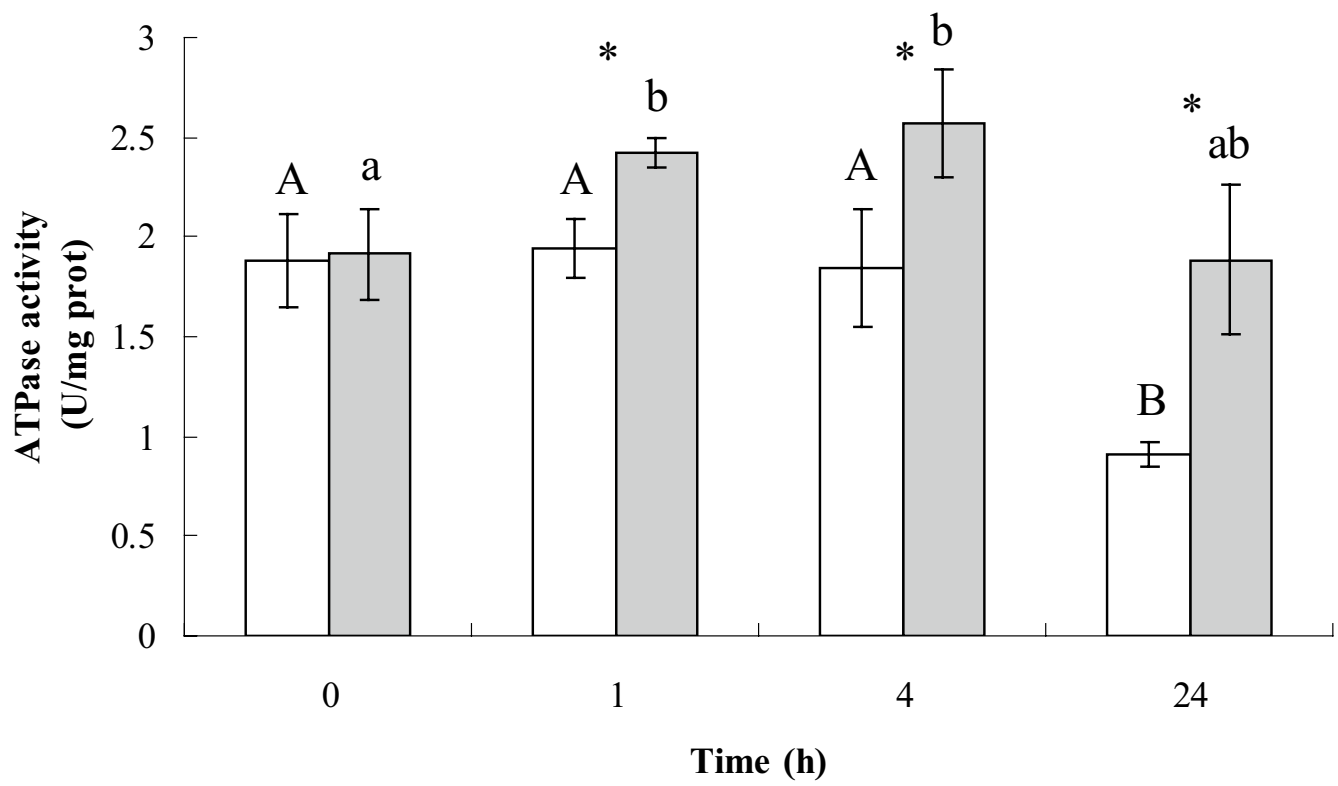

Fig. 1 ATPase activities of E. coli CFT073 in control group and exposed group. Different small letters indicate significant differences in the exposed group among different times ( $P<0.05)$; different capital letters indicate significant differences in control group among different times $(P<0.05)$; the asterisk indicates significant differences between the control group and exposed group at the same moment $(P<0.05)$, and bars represent standard deviations of the means, the same below

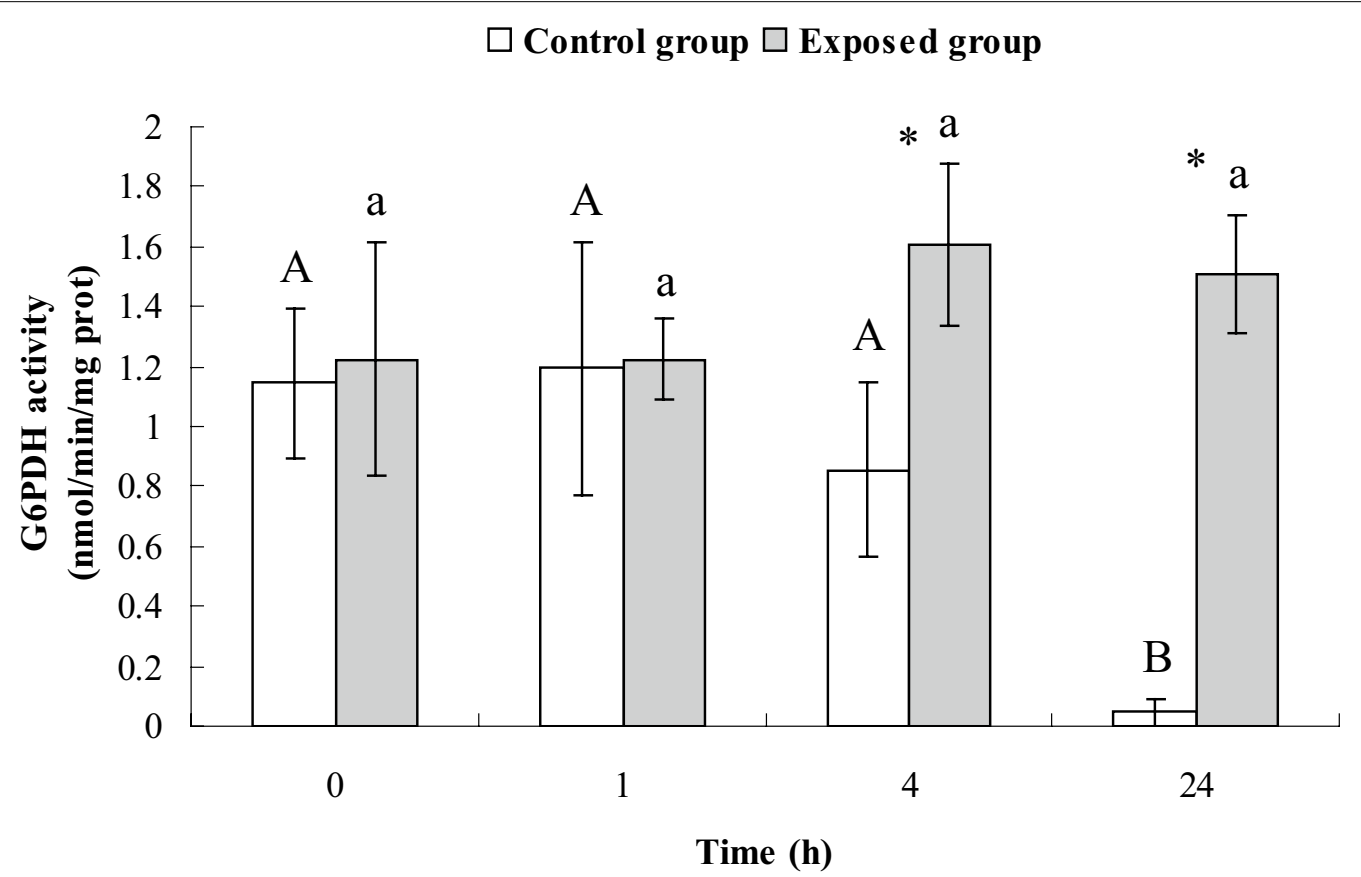

Fig. 2 G6PDH activities of E. coli CFT073 in control group and exposed group 


\section{Control group $\square$ Exposed group}

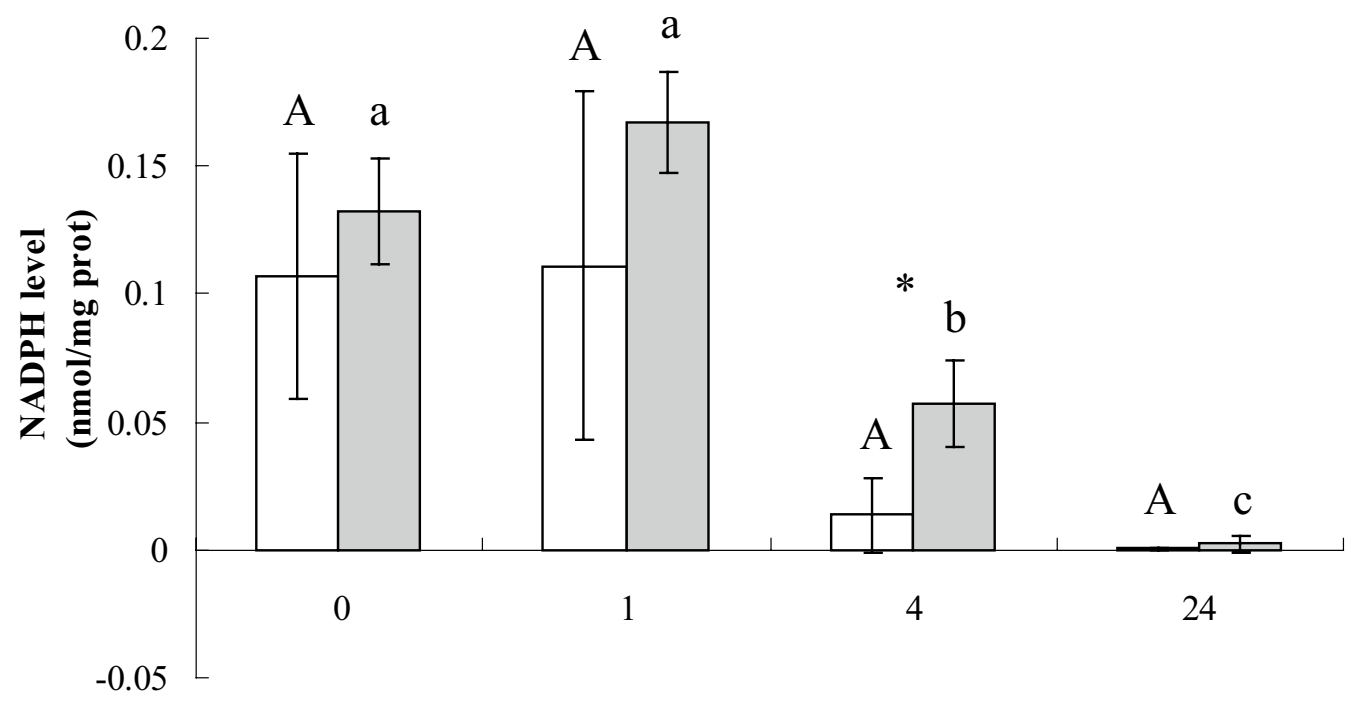

Time (h)

Fig. 3 NADPH levels of E. coli CFT073 in control group and exposed group

(Zhu et al. 1994). There have been some successful cases of DM used in the aquaculture industry in China. DM was used to treat eel (Anguilla japonica) skin ulceration disease caused by a pathogenic fungus, Protoachlya paradoxa, with a cure rate of $100 \%$. Additionally, no fish fatalities were resulting from DM toxicity, suggesting that $\mathrm{DM}$ is harmless to fish at the effective bactericidal concentration (Chen 2010). Another study confirmed that the safe dose of DM for juvenile Odontobutis potamophila was higher than the conventional dose, indicating that it could be used in its seed-rearing (Liu et al. 2019).

Zhu et al. (1994) showed that DM was not subject to decomposition below $70{ }^{\circ} \mathrm{C}$, but could be decomposed rapidly above $70{ }^{\circ} \mathrm{C}$. The temperature during the preparation of DM stock solution in this study was below $70^{\circ} \mathrm{C}$.

The spontaneous elimination effect of DM at different $\mathrm{pH}$ and temperatures in water has also been investigated (Wu et al. 2015). The results indicated that it was stable under acidic conditions but was easy to decompose above $\mathrm{pH}$ 8.5. The available experimental data showed that DM could not be detected after a day in water at $\mathrm{pH} 8.5$ and it could not also be detected after five days in water at $\mathrm{pH} 8$, measured using Ultra Performance Liquid Chromatography method. Furthermore, with the increase of water temperature, the elimination rate of DM increased, and it could not be detected after twelve days in water at $35{ }^{\circ} \mathrm{C}$. Although DM had its limitations since it was only suitable for environments with $\mathrm{pH}$ less than 8.5 and it needed to be stored at low temperature, there was evidence that DM could destroy the cellular structure of microorganisms and disturb physiological functions within a few hours (Singh et al. 2006), meaning that its bactericidal capacity was not affected by spontaneous elimination.

The inhibitory ability of DM against the tested $E$. coli strains In recent years, studies on the inhibitory ability of DM against microorganisms have been focused on the inhibitory effect of this agent against pathogenic fungi in vitro. The effective inhibitory concentration of DM on mycelial growth, sporangia formation, zoospores release and germination of pathogenic Saprolegnia sp., isolated from the crucian carp eggs, was $1 \mathrm{mg} / \mathrm{L}, 0.5 \mathrm{mg} / \mathrm{L}, 1 \mathrm{mg} / \mathrm{L}$ and $0.5 \mathrm{mg} / \mathrm{L}$, respectively (Xia 2011). Another study showed that the MIC value of this agent against another strain of Saprolegnia sp. from diseased sturgeons was $6.25 \mathrm{mg} / \mathrm{L}$ (Zhang 2011). DM, at a concentration range of $0.25-$ $1.25 \mathrm{mg} / \mathrm{L}$, significantly inhibited the production of zoospore of Saprolegnia ferax (Cao et al. 2012).

However, to our present knowledge, the antibacterial effect of DM on bacteria is unclear. In the present study, DM showed remarkable antibacterial activity against the tested $E$. coli strains, which provided a reference for its application as a new efficient disinfectant to the prevention of $E$. coli infections, especially when faced with increasingly severe bacterial resistance to common disinfectants. 

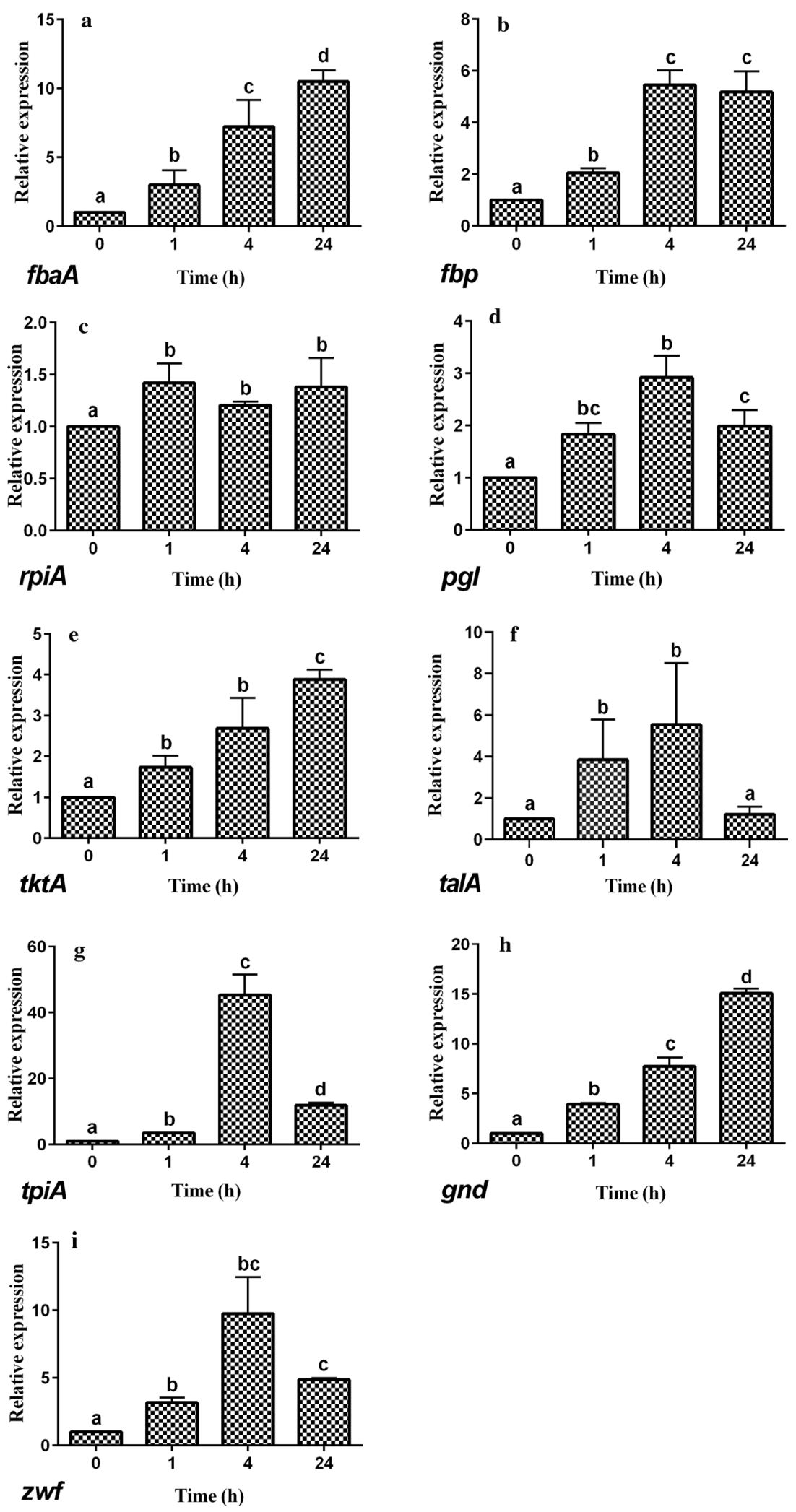

Fig. 4 Relative expression of genes in hexose monophosphate pathway of E. coli CFT073 exposed to dithiocyano-methane. Different small letters indicate significant differences in exposed group among different times $(P<0.05)$, and bars represent standard deviations of the means 

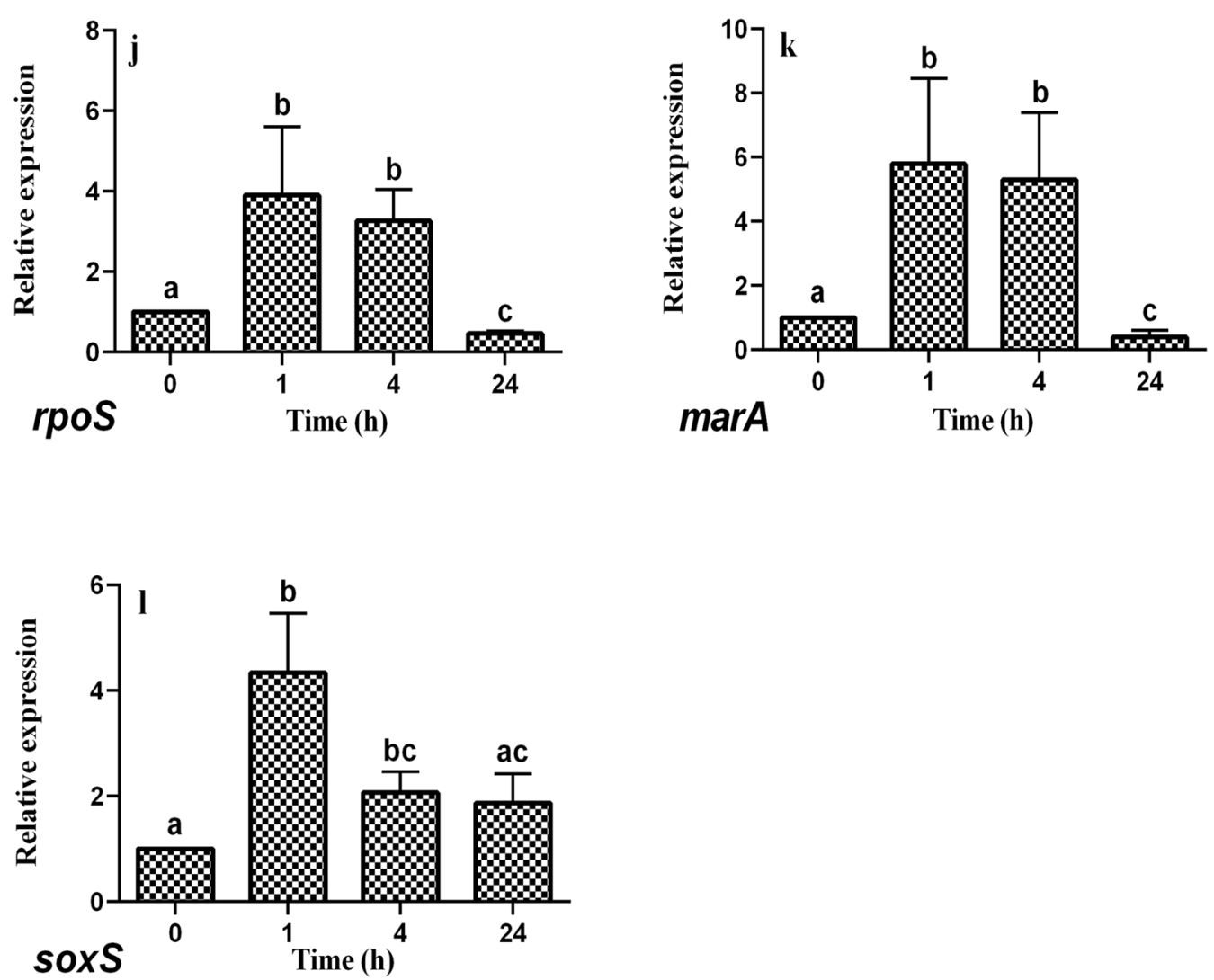

Fig. 5 Relative expression of genes related to stress response of E. coli CFT073 exposed to dithiocyano-methane. Different small letters indicate significant differences in exposed group among different times $(P<0.05)$, and bars represent standard deviations of the means

DM at a lethal concentration of $10 \times$ MIC inhibited mainly the pathway of glucose decomposition of E. coli CFT073 The current study demonstrated the respiration inhibition rate of DM to E. coli CFT073 was $(42.73 \pm 2.39) \%$. The $\mathrm{O}_{2}$ consumption of the tested strain decreased after exposed to DM. Singh et al. (2006) also reported that the rate of $\mathrm{O}_{2}$ consumption of fungus $O$. floccosum reduced when exposed to DM at concentrations higher than $1 \mathrm{mmol} / \mathrm{L}$. Furthermore, DM inhibited the respiration of some fungus such as Saccharomyces cerevisiae by affecting the function of mitochondria and the activity of NADH oxidase (Chen et al. 2004). Fungal respiration depends mainly on mitochondria, but bacteria are lack of such organelle. These results suggest DM inhibits fungal and bacterial respiration via a different mechanism.

Iodine acetic acid, malonic acid and sodium phosphate is the typical respiratory inhibitor of the EMP pathway, TCA pathway and HMP pathway, respectively (Guo et al. 2005; Ma et al. 2010; Qu et al. 2015). If two inhibitors block the same pathway, the superposition of the inhibitory rate is weak. On the other hand, if they block different pathways, the superposition increases significantly.
The result of the respiration inhibition test in this study indicated that DM at a lethal concentration of $10 \times$ MIC inhibited mainly HMP pathway. Studies have shown that HMP pathway in $E$. coli not only plays a role in the decomposition of glucose but also provides cells with many intermediates for the anabolism, including amino acids, nucleotides and polysaccharides (Sprenger 1995; Zhao et al. 2004). If this pathway is blocked, the production of essential metabolites for biosynthesis in bacterial cells will be inhibited, resulting in the physiological disorder of bacteria (Additional file 1) (Wang et al. 2002).

\section{Potential correlation among ATPase, G6PDH, NADPH} and the effect of DM at a concentration of MIC on them It was reported that a transformation relationship between two nicotinamide adenine dinucleotides existed in liver mitochondria of rats (Kaplan et al. 1956), as shown in the following equation:

$$
N A D P H+N A D^{+} \rightleftharpoons N A D P^{+}+N A D H
$$


During ATP hydrolysis by ATPase, the equilibrium in above equation strongly shifted to the left (Drachev et al. 1980), resulting in an increase of NADPH. These studies revealed an indirect relationship between ATPase and NADPH in mammals. In addition, the transformation relationship represented by the above equation was also found in Rhodospirillum rubrum (Kondrashin et al. 1980). However, it is unclear whether such a relationship between ATPase and NADPH also exists in E. coli.

A previous study demonstrated that ATPase activities in red blood cell membranes of patients with G6PDH deficiency were lower than those of normal people (Jiang et al. 1991), indicating a relationship between ATPase and G6PDH in the human body. In our study, both G6PDH activities and ATPase activities in the exposed group did not change significantly between 1 and $24 \mathrm{~h}$, supporting this proposed relationship between ATPase and G6PDH activity.

Four hours after exposure, both the activity of G6PDH and the levels of NADPH in the exposed group were significantly higher than those in control group (Figs. 2 and 3 ). This is likely because bacteria were in the logarithmic growth phase with sufficient glucose in the medium, so glucose metabolism was active in the bacteria. After $24 \mathrm{~h}$ of exposure, G6PDH activity remained higher in the exposed group than the control group. However, there were lower levels of NADPH (Figs. 2 and 3). At this time, the bacteria were in the decline growth phase with a depleted supply of glucose in the medium and could only produce a limited amount of NADPH. Subsequently, NADPH was consumed to maintain the metabolic activity of bacteria in response to the DM insult, leading to a decrease in NADPH level.

In the HMP pathway, NADPH competes with NAPD ${ }^{+}$ to bind to the active site of G6PDH. Therefore, G6PDH activity is directly affected by the ratio of $\mathrm{NAPD}^{+} /$ $\mathrm{NADPH}$. In the present study, after exposure to DM at a concentration of MIC, NADPH level in the exposed group at $24 \mathrm{~h}$ significantly decreased compared to $1 \mathrm{~h}$, promoting G6PDH activity. However, once NADPH became excessive, it in turn inhibited G6PDH activity. This might explain our result that G6PDH activities in the exposed group did not change a lot between 1 and $24 \mathrm{~h}$.

The primary function of ATPase in living organisms is to catalyze the hydrolysis of ATP to form ADP and phosphate $(\mathrm{Pi})$ and release energy (Bolognani et al. 1993). The increased ATPase activities observed in this study could indicate an increase in ATP hydrolysis. The activation of the HMP pathway by DM at a concentration of MIC would further consume more ATP in order to catalyze glucose to form more glucose-6-phosphate using hexokinase. The combination of the above two reactions resulted in an increase in ATP consumption. This result is in line with the finding by Singh et al. (2006) showing the ATP level in microbial cells reduced after exposure to DM.

\section{Reasons for the increase of G6PDH activities, NADPH level and gene expression levels in HMP pathway after exposure to DM at a concentration of MIC}

In the present study, DM at a lethal concentration of $10 \times$ MIC inhibited the HMP pathway in the respiratory metabolism of E. coli. In contrast, DM at a concentration of MIC activated this pathway, increasing bacterial key enzyme activities and gene expression levels. This observation is generally consistent with a previous study showing that DM at low concentrations had little effect on fungal respiration, but inhibited it at high concentrations (Singh et al. 2006).

Iida et al. (1993) showed that there were two transketolases ( $t k t A$ and $t k t B$ ) responsible for erythrose 4-phosphate (E4P) synthesis. Transketolase A encoded by $t k t A$ plays a significant role in E4P production in the HMP pathway. Overexpression of $t k t A$ increases the yield of E4P (Tatarko and Romeo 2001), which is essential for the biosynthesis of aromatic amino acids, such as phenylalanine, tyrosine and tryptophan. The main metabolic pathway of phenylalanine is to produce tyrosine via hydroxylation. And tyrosine undergoes a series of catabolism to form fumaric acid to enter the tricarboxylic acid cycle. In addition, acetoacetyl coenzyme $\mathrm{A}$, one of the end products of tryptophan catabolism, is formed by thiolase, which indicates a link between aromatic amino acids and tricarboxylic acid cycle. Moreover, the transketolase in the HMP pathway is also closely related to the production of intermediates such as ribose 5-phosphate and heptanose 7-phosphate. The former is employed for the biosynthesis of purine and pyrimidine nucleotides, and the latter is utilized for the biosynthesis of bacterial cytoderm components (Iida et al. 1993; Maifiah et al. 2017). In summary, the up-regulation of $t k t A$ gene expression was presumably due to the accelerated biosynthesis of the essential substances to maintain the physiological functions in $E$. coli in response to the stress induced by DM insult. It was reported the E. coli rpoS gene encoded a sigma factor, RpoS, which was required for an expression of a large number of genes in response to various stresses (Stoebel et al. 2009). In E. coli, rpoS positively regulated the expression of $t k t A$ gene in the exponential growth phase, but negatively in the stationary growth phase (Jung et al. 2005). Our study showed that the stress in response to DM insult led to the up-regulation of rpoS expression in E. coli in the exponential growth phase $(1 \mathrm{~h}$ and $4 \mathrm{~h}$ ), and subsequently, the up-regulation of 
$t k t A$ expression. When the expression of $r p o S$ in $E$. coli in the stationary growth phase declined at $24 \mathrm{~h}$ after exposure, $t k t A$ expression remained increased.

G6PDH played an essential role for $E$. coli to survive the stress induced by antibacterial agents. It has been demonstrated that the levels of G6PDH increased by the induction of $z w f$ gene after cells were exposed to paraquat (Niazi et al. 2007). Tellurite-exposed $E$. coli also exhibited increased $z w f$ expression, G6PDH activity and NADPH level (Sandoval et al. 2011, 2015), which was in line with the results in the present study. MarA and SoxS in E. coli, members of the AraC transcriptional activator family, also responded to stimuli such as the presence of antibacterial agents (Duval and Lister 2013). In E. coli, transcription of $z w f$ gene was activated by MarA or SoxS in response to stress conditions (Jair et al. 1995; Fawcett and Wolf 1995). These data validate the up-regulation of $t k t A$ and $z w f$ expression in E. coli CFT073 after exposed to DM in our study.

In summary, the low MIC and $\mathrm{MBC}$ of $\mathrm{DM}$ in this study demonstrates DM as an effective bactericidal agent and its potential in preventing pathogenic $E$. coli infections. Unique properties of DM aqueous solution, including its effectiveness as a bactericide, its degradability and its low residue in the environment, indicate that it can potentially be used as a disinfectant in settings such as hospitals, communities and farms.

\section{Supplementary information}

Supplementary information accompanies this paper at https://doi. org/10.1186/s13568-020-01142-z.

Additional file 1. Schematic diagram of the hexose monophosphate pathway.

\begin{abstract}
Abbreviations
DM: Dithiocyano-methane; E. coli: Escherichia coli; G6PDH: Glucose-6-phosphate dehydrogenase; NADPH: Nicotinamide adenosine denucleotide hydro-phosphoric acid; RT-qPCR: Real-time quantitative polymerase chain reaction; MIC: Minimum inhibitory concentration; $\mathrm{MBC}$ : Minimum bactericide concentration; HMP: Hexose monophosphate pathway.
\end{abstract}

\section{Acknowledgements}

Here I would like to thank Dr. Liu Canying from Foshan University for the gift of E. coli strains.

\section{Authors' contributions}

YF Chen, HYu and YS Tan conceived and designed research. WJ Ke and HB Qin conducted experiments. LM Qin and Y Yang helped to conduct experiments. SW Chen analyzed data. YF Chen and YS Tan wrote the paper. All authors read and approved the final manuscript.

\section{Funding}

This work was supported by the Natural Science Foundation of Guangdong (2017A030310642), the Science and Technology Planning Project of Guangdong Province (2016A020210141, 2017A020208079), the Guangdong Provincial Key Laboratory of Animal Molecular Design and Precise Breeding (2019B030301010), and the Key Laboratory of Animal Molecular Design and Precise Breeding of Guangdong Higher Education Institutes (2019KSYS011).
Availability of data and materials

All relevant data are within the manuscript.

Ethics approval and consent to participate

Not applicable.

\section{Consent for publication}

Not applicable.

\section{Competing interests \\ The authors declare that they have no competing interests.}

Received: 13 July 2020 Accepted: 2 November 2020

Published online: 11 November 2020

\section{References}

Bolognani L, Majni G, Costato M, Milani M (1993) ATPase and ATPsynthetase activity in myosin exposed to low power laser and pulsed electromagnetic fields. Bioelectroch Bioenergy 32:155-164. https://doi. org/10.1016/0302-4598(93)80033-Q

Boudeau J, Glasser AL, Masseret E, Joly B, Darfeuille-Michaud A (1999) Invasive ability of an Escherichia coli strain isolated from the ileal mucosa of a patient with Crohn's disease. Infect Immun 67:4499-4509. https://doi. org/10.1128/IAl.67.9.4499-4509.1999

Braun C, Birck R, Singer MV, Schnuelle P, van der Woude FJ, Löhr M (2006) Life-threatening intoxication with methylene bis(thiocyanate): clinical picture and pitfalls. A case report BMC Emerg Med 6:5. https://doi. org/10.1186/1471-227X-6-5

Cao HP, Zheng WD, Xu JL, Ou RJ, He S, Yang XL (2012) Identification of an isolate of Saprolegnia ferax as the causal agent of saprolegniosis of Yellow catfish (Pelteobagrus fulvidraco) eggs. Vet Res Commun 36:239-244. https ://doi.org/10.1007/s11259-012-9536-8

Chen CJ, Zhou MG, Ye ZY (2003) The mechanism of organic thiocyanic chemicals: methylene dithiocyanate to Fusarium moniliforme microbes. Acta Phytopathol Sin 33:48-51. https://doi.org/10.3321/j. issn:0412-0914.2003.01.010

Chen CJ, Zhou MG, Wang JX, Ye ZY (2004) Effects of metheylene dithiocyanate to Saccharomyces cerevisiae. J Nanjing Agric Univ 27:51-54. https://doi. org/10.7685/j.issn.1000-2030.2004.01.012

Chen $\mathrm{L}$ (2010) The primary pathogen and treatment test for the skin ulceration disease of Anguilla japonica. Dissertation, Fujian Agriculture and Forestry University.

Chen L, Xia DJ (2013) Comparison of disinfectant-resistant genes in Escherichia coli between hospital-acquired infection and community-acquired infection. Chin J Microecol. 25:168-170. https://doi.org/10.13381/j.cnki. cjm.2013.02.014

Drachev LA, Kondrashin AA, Semenov AY, Skulachev VP (1980) Reconstitution of biological molecular generators of electric current transhydrogenase. Eur J Biochem 113:213-217. https://doi.org/10.1111/j.1432-1033.1980. tb06158.x

Duval V, Lister IM (2013) MarA, SoxS and Rob of Escherichia coli Global regulators of multidrug resistance, virulence and stress response. Int J Biotechnol Wellness Ind 2:101-124. https://doi. org/10.6000/1927-3037.2013.02.03.2

Fawcett WP, Wolf RE (1995) Genetic Definition of the Escherichia coli zwf "'Soxbox"', the DNA Binding Site for SoxS-mediated induction of glucose 6-phosphate dehydrogenase in response to superoxide. J Bacteriol 177:1742-1750. https://doi.org/10.1128/jb.177.7.1742-1750.1995

Frydendahl K (2002) Prevalence of serogroups and virulence genes in Escherichia coli associated with postweaning diarrhoea and edema disease in pigs and a comparison of diagnostic approaches. Vet Microbiol 85:169-182. https://doi.org/10.1016/S0378-1135(01)00504-1

Guo T, Ma YL, Guo P, Xu ZR (2005) Antibacterial effects of the Cu(II)-exchanged montmorillonite on Escherichia coli K88 and Salmonella choleraesuis. Vet Microbiol 105:113-122. https://doi.org/10.1016/j.vetmic.2004.11.003

Hu YH, Zheng WJ, Sun L (2010) Identification and molecular analysis of a ferritin subunit from red drum (Sciaenops ocellatus). Fish Shellfish Immu 28:678-686. https://doi.org/10.1016/j.fsi.2010.01.001 
Ibrahim WA, Marouf SA, Erfan AM, Nasef SA, Jakee JK (2019) The occurrence of disinfectant and antibiotic-resistant genes in Escherichia coliisolated from chickens in Egypt. Vet World 12:141-145. https://doi.org/10.14202/vetwo rld.2019.141-145

lida A, Teshiba S, Mizobuchi K (1993) Identification and characterization of the tktB gene encoding a second transketolase in Escherichia coli K-12. J Bacteriol 175:5375-5383. https://doi.org/10.1128/jb.175.17.5375-5383.1993

Jair KW, Martin RG, Rosner JL, Fujita N, Ishihama A, Wolf RJ (1995) Purification and regulatory properties of MarA protein, a transcriptional activator of Escherichia coli multiple antibiotic and superoxide resistance promoters. J Bacteriol 177:7100-7104. https://doi.org/10.1128/ jb.177.24.7100-7104.1995

Jiang WY, Tian XY, Zhou XZ (1991) Study on ATPase activity of erythrocyte membrane in patients with G6PD deficiency. Chin J Pathophysiol 5:453-456

Jung IL, Phyo KH, Kim IG (2005) RpoS-mediated growth-dependent expression of the Escherichia coli tkt genes encoding transketolases isoenzymes. Curr Microbiol 50:314-318. https://doi.org/10.1007/s00284-005-4501-1

Kaplan NO, Swartz MN, Frech ME, Ciotti MM (1956) Phosphorylative and nonphosphorylative pathways of electron transfer in rat liver mitochondria. Proc Natl Acad Sci USA 42:481-487. https://doi.org/10.1073/pnas.42.8.481

Kondrashin AA, Remennikov VG, Samuilov VD, Skulachev VP (1980) Reconstitution of biological molecular generators of electric current inorganic pyrophosphatase. Eur J Biochem 113:219-222. https://doi. org/10.1111/j.1432-1033.1980.tb06159.x

Kwak MJ, Kim MS, Kwon SK, Cho SH, Kim JF (2016) Genome sequence of Escherichia coli NCCP15653, a group D strain isolated from a diarrhea patient. Gut Pathog 8:1-7. https://doi.org/10.1186/s13099-016-0084-6

Li S, Qu Y, Hu D, Shi YX (2012) Comparison of extended spectrum B-lactamases-producing Escherichia coli with non-ESBLs-producing E. coli: drug-resistance and virulence. World J Emerg Med 3:208-212. https://doi. org/10.5847/wjem.j.issn.1920-8642.2012.03.009

Liu GX, Zheng Y, Li CN, Peng G, Hao C, Ding SY, Shi YB (2019) Acute toxicity of four aquacultural drugs to juvenile dark sleeper (Odontobutis potamophila). J Anhui Agric Sci 47:103-106. https://doi.org/10.3969/j. issn.0517-6611.2019.23.030

Ma YL, Yang B, Guo T, Xie L (2010) Antibacterial mechanism of $\mathrm{Cu}^{2+}-\mathrm{ZnO}$ / cetylpyridinium-montmorillonite in vitro. Appl Clay Sci 50:348-353. https ://doi.org/10.1016/j.clay.2010.08.025

Maifiah MHM, Creek DJ, Nation RL, Forrest A, Tsuji BT, Velkov T, Li J (2017) Untargeted metabolomics analysis reveals key pathways responsible for the synergistic killing of colistin and doripenem combination against Acinetobacter baumannii. Sci Rep 7:45527. https://doi.org/10.1038/srep45527

Mellata M, Dho-Moulin M, Dozois CM III, RC, Lehoux B, Fairbrother JM, (2003) Role of avian pathogenic Escherichia coli virulence factors in bacterial interaction with chicken heterophils and macrophages. Infect Immun 71:494-503. https://doi.org/10.1128/iai.71.1.494-503.2003

NCCLS (2000) Methods for Dilution Antimicrobial Susceptibility Tests for Bacteria That Grow Aerobically: Approved Standard, fifth ed., NCCLS document M7-A5 (ISBN 1-56238-394-9). NCCLS, Pennsylvania, USA.

Niazi JH, Kim BC, Gu MB (2007) Characterization of superoxide-stress sensing recombinant Escherichia coli constructed using promoters for genes zwf and fpr fused to lux operon. Appl Microbiol Biot 74:1276-1283. https:// doi.org/10.1007/s00253-006-0758-y

Qi ZQ, Chen CJ, Wang JX, Zhou MG (2008) Mode of action of methylene bisthiocyanate and its decomposition products to Meloidogyne spp. juveniles. Acta Phytopathol Sin 38:420-424. https://doi.org/10.3321/j. issn:0412-0914.2008.04.014
Qi ZQ, Wang JX, Chen CJ, Zhou MG (2006) Efficacy of the methylene bisthiocyanate formulation, $4.2 \% \mathrm{MBT} E C$, as a potentially novel nematicide for the control of root-knot nematode. Australas Plant Path 35:733-737. https:// doi.org/10.1071/AP06072

Qu M, Tong C, Kong L, Yan X, Chernikov OV, Lukyanov PA, Jin Q, Li W (2015) Purification of a secreted lectin from Andrias davidianus skin and its antibacterial activity. Comp Biochem Physiol C 167:140-146. https://doi. org/10.1016/j.cbpc.2014.08.008

Sandoval JM, Arenas FA, Vásquez CC (2011) Glucose-6-Phosphate dehydrogenase protects Escherichia coli from Tellurite-mediated oxidative stress. PLoS ONE 6:e25573. https://doi.org/10.1371/journal.pone.0025573

Sandoval JM, Arenas FA, García JA, Díaz-Vásquez WA, Valdivia-González M, Sabotier M, Vásquez CC (2015) Escherichia coli 6-phosphogluconate dehydrogenase aids in tellurite resistance by reducing the toxicant in a NADPH-dependent manner. Microbiol Res 177:22-27. https://doi. org/10.1016/j.micres.2015.05.002

Singh T, Kreber B, Singh A, Stewart A, Jaspers M (2006) Microscopic, biochemical and physiological assessment of the effect of methylene bisthiocyanate on the sapstain fungus Ophiostoma floccosum. Eur J Plant Pathol 114:317-328. https://doi.org/10.1007/s10658-005-5997-8

Sprenger GA (1995) Genetics of pentose-phosphate pathway enzymes of Escherichia coli K-12. Arch Microbiol 164:324-330. https://doi. org/10.1007/BF02529978

Stoebel DM, Hokamp K, Last MS, Dorman CJ (2009) Compensatory Evolution of Gene Regulation in Response to Stress by Escherichia coli Lacking RpoS. PLoS Genet 5:1-9. https://doi.org/10.1371/journal.pgen.1000671

Tatarko M, Romeo T (2001) Disruption of a global regulatory gene to enhance central carbon flux into phenylalanine biosynthesis in Escherichia coli. Curr Microbiol 43:26-32. https://doi.org/10.1007/s002840010255

Wang JY, Zhu SG, Xu CF (2002) Biochemistry, 3rd edn. Higher Education Press, Beijing

Woodward MJ, Kearsley R, Wray C, Roeder PL (1990) DNA probes for the detection of toxin genes in Escherichia Coli isolated from diarrhoeal disease in cattle and pigs. Vet Microbiol 22:277-290. https://doi.org/10.1016/03781135(90)90115-C

Wu J, Hu Q, Lin G, Cen W (2015) Effects of Temperature, pH and COD on the elimination of Methylene dithiocyanate in water. J Fujian Nor Univ $31: 77-84$

Xia WW (2011) Isolation, dentification and biological characteristics of a pathogenic Saprolegnia sp. from the crucian carp eggs. Dissertation, Shanghai Ocean University.

Yang QE, Li L, Liao XP, Li XP, Wang MR, Wan Q, Liu YH, Sun J (2015) Prevalence of resistance to disinfectants and antibiotics in Escherichia coli isolated from the swine and farm environment. J South Chin Agric Univ 36:15-22. https://doi.org/10.7671/j.issn.1001-411X.2015.06.003

Zhang SQ (2011) The screening for the anti-Saprolegnia drugs and application effects of the preparation. Dissertation, Shanghai Ocean University.

Zhao J, Baba T, Mori H, Shimizu K (2004) Global metabolic response of Escherichia coli to gnd or zwf gene-knockout, based on ${ }^{13} \mathrm{C}$-labeling experiments and the measurement of enzyme activities. Appl Microbiol Biot 64:91-98. https://doi.org/10.1007/s00253-003-1458-5

Zhu Y, Ge YT, Chen XF (1994) Determination of the decomposition of microbicide Methylene dithiocyanate. Water Purif Technol 3:29-32. https://doi. org/10.15890/j.cnki.jsjs.1994.03.008

\section{Publisher's Note}

Springer Nature remains neutral with regard to jurisdictional claims in published maps and institutional affiliations. 